\title{
Flerspråkighet och tanke
}

\author{
Av EMANUEL BYLUND
}

\begin{abstract}
Bylund, Emanuel, manne.bylund@biling.su.se, Professor, Centre for Research on Bilingualism, Stockholm University \& Department of General Linguistics, Stellenbosch University: "Multilingualism and thought." Språk och stil NF 31:1, 2021, pp. 143-165.

Does language influence the way we think and reason about reality? If so, what happens if you speak more than one language? These questions have been at the centre stage of the field of psycholinguistics since the early 2000's. The aim of this article is to review the state-of-the-art in research on language and thought, focusing particularly on multilingualism. First, a historical overview of the field is provided, which serves as the backdrop against which current findings on multilingualism and cognitive processing are discussed. Subsequently, the article analyses how biographical variables, such as language proficiency, age of acquisition, and frequency of language use, may modulate the way in which language influences multilingual thought. The article closes by discussing specific issues in research on language and thought that merit further study.
\end{abstract}

Keywords: cognition, language, linguistic relativity, multilingualism, Whorf.

Påverkar språket vårt sätt att tänka? Om så är fallet, betyder det då att talare av olika språk uppfattar verkligheten på olika sätt? Och, vad händer om man talar mer än ett språk, skiftar verklighetsuppfattningen i så fall beroende på vilket språk man använder? Låt oss illustrera dessa frågor med ett exempel. I germanska och romanska språk talar man om tidsflödet som om det sker i en given riktning längs en horisontell axel: det förflutna ligger »bakom» oss och framtiden ligger - just precis - »framför» oss. Å andra sidan, på aymara, som talas i Bolivia, Chile och Peru, är riktningen den omvända: dåtiden talas om som om den ligger framför talaren, och framtiden som om den ligger bakom talaren (ordet för 'framtid' innehåller morfemet quipa, vilket betyder 'bakom') (Núñez \& Sweetser 2006). Innebär dessa skillnader i tidsuttryck att talare av aymara och spanska, exempelvis, faktiskt tänker annorlunda om tid, och hur tänker i så fall tvåspråkiga talare av spanska och aymara?

Relationen mellan språk och tanke är för närvarande föremål för vetenskapliga undersökningar i ett antal olika discipliner, såsom språkvetenskap, psykologi, neurovetenskap, filosofi och socialantropologi. Frågan om huruvida talare av olika språk tänker annorlunda, så kallad språklig relativism, har dryf- 


\section{4}

tats sedan antikens dagar och kan sägas vara lika gammal som västerländskt tänkande. Men relationen mellan flerspråkighet och tanke har uppseendeväckande nog inte varit föremål för samma intensiva forskning (t.ex. Pavlenko 2005, Bylund \& Athanasopoulos 2014b, Athanasopoulos \& Bylund 2020). Så vad är då svaret på frågan om huruvida flerspråkiga talare tänker annorlunda beroende på vilket språk de använder? Som med den mesta forskningen kring språklig relativism måste svaret bli: »Det beror på ...».

Syftet med föreliggande artikel är att med utgångspunkt $\mathrm{i}$ empirisk evidens diskutera relationen mellan språk och tanke, med särskild fokus på flerspråkighet. I denna diskussion kommer det att framgå att frågor kring språk och tanke - av den typ som ställs ovan - sällan kan besvaras med ett enkelt ja eller nej, utan i stället måste benas upp i mer specifika frågeställningar med tydligt definierade begrepp för att kunna beforskas.

Artikelns disposition är som följer: först ges en historisk tillbakablick på forskning kring språk och tanke. Därefter redogörs för de landvinningar som har gjorts under de senaste årtiondenas forskning kring språklig relativism. Mot bakgrund av detta diskuteras sedan flerspråkighet och tanke, med avseende på specifika kognitiva beteenden och de faktorer i individens språkliga bakgrund som ger upphov till dem.

\section{Framväxten av forskning kring språk och tanke}

En av de första kända texterna som rör vid relationen mellan språk och tanke är samlingsverket Historiae (444 f. Kr., se Fishman 1960), i vilket historikern Herodotos anmärker på det faktum att man på grekiska skriver från vänster till höger, medan man på egyptiska skriver från höger till vänster. Detta, ansåg han, kunde vara en bidragande orsak till varför de två kulturerna så ofta låg $\mathrm{i}$ fejd med varandra. Herodotos visade sig, med andra ord, vara öppen för möjligheten att språkets karakteristik (i detta fall skriftspråket särdeles) kan utöva något slags påverkan på människans beteende. Hans inställning stod i kontrast med andra tidiga tänkare, såsom Aristoteles eller Sankt Augustinus, vilka ansåg att språket inte var mer än ett verktyg för att tala om verkligheten, utan konsekvenser för vår uppfattning av den (t.ex. Allan 2004).

Århundradena som följde Antiken såg endast enstaka ansatser till att utröna språkets inflytande på tanken, och det var inte förrän långt senare som mer systematiska studier kom att genomföras. Under 1800-talet gjorde exempelvis 
den tyske filologen Wilhelm von Humboldt (t.ex. 1836/1988) flera iakttagelser om språk och tanke i sina texter, och ansåg bl.a. att människan enbart interagerar med sin omgivning på de premisser som språket ger henne. Detta, menade von Humboldt, får som följd att människans uppfattning av verkligheten hela tiden förmedlas genom språket. Under det tidiga 1900-talet kom forskningen kring språk och tanke att på allvar börja spira. Denna utveckling ägde främst rum i USA under ledning av antropologer och språkvetare, med Franz Boas som förgrundsgestalt. I sitt alster Handbook of American Indian Languages (1911) diskuterade Boas den språkliga mångfaldens eventuella effekter på upplevelsen av verkligheten. En konsekvens av tvärspråklig variation i grammatiska och lexikala kategorier, hävdade han, var att talare av olika språk på ett omedvetet plan måste fästa uppmärksamhet vid olika aspekter av verkligheten under själva talakten. Exempelvis, för att beskriva ett enkelt skeende, såsom en kvinna som dricker kaffe, måste talare av ryska koda huruvida situationen är pågående eller avslutad (grammatisk aspekt), talare av det pomoanska språket kashaya (USA) måste koda huruvida de bevittnat skeende själva eller ej (grammatisk evidentialitet), talare av ponca (siouxspråk, USA) huruvida kvinnan var stilla eller i rörelse, och talare av svenska kodar ofta huruvida kaffet intogs stående eller sittande (dvs. genom serieverbskonstruktioner). Samtliga av dessa kodningar visar enligt Boas sätt att tänka att språkspecifika kategorier speglar selektiv uppmärksamhet.

En av Boas studenter, Edward Sapir, ägnade sig åt att utveckla denna tankegång och kom så småningom att hävda att språket inte bara tvingar dess talare att verbalisera särskilda aspekter av verkligheten, utan också kanaliserar talarens upplevelse av verkligheten (Sapir 1921). Sapir gick således längre än Boas i sitt resonemang i det att han uttalade sig om språkliga kategoriers inverkan på tanken. Denna syn utvecklades i sin tur av en av Sapirs studenter, Benjamin Lee Whorf, som kom att bli det namn som förknippas mest med idén att språket påverkar tanken. Influerad av Einsteins relativitetsteori myntade Whorf begreppet 'språklig relativism':

The linguistic relativity principle [...] means, in informal terms, that users of markedly different grammars are pointed by their grammars toward different types of observations and different evaluations of externally similar acts of observation, and hence are not equivalent as observers but must arrive at somewhat different views of the world. (Whorf $1956 \mathrm{s.} \mathrm{338)}$

Denna princip framhåller således att talare av språk med skilda grammatiska kategorier ser världen på något olika sätt. Whorfs forskargärning var kanske 
som mest betydelsefull på den teoretiska sidan, då hans empiriska ansatser - i den mån de alls förekom - sällan var grundade i rigoröst metodologiskt förfarande. Ett generellt problem med tidiga ansatser var just en sammansmältning av observation och konklusion: Talare av olika språk tänker annorlunda. Och hur vet man det? Jo, för att de talar annorlunda (Pinker 1994). I en tidig studie påtalade Lenneberg (1953) dessa metodologiska svagheter och underströk vikten av att ha ett oberoende sätt att mäta tanke som var fritt från språkliga beskrivningar och språkbruk. Lenneberg och Roberts (1956) testade detta i en studie genom att undersöka huruvida variation i färgtermer i språken engelska och zuni (språkisolat, USA) ger upphov till motsvarande variation i färgkategorisering och -minne hos talare av dessa språk. Resultaten tycktes visa att så var fallet.

Vad som kunde ha blivit ett rejält metodologiskt uppsving för studiet av språklig relativism kom dock att klinga av, då forskningen - delvis i kölvattnet av andra världskrigets etniska rensningar - i stället riktade fokus på vad som var universellt i det mänskliga sinnet, oavsett kulturell eller språklig bakgrund. Den generativa grammatikens intåg i lingvistiken (t.ex. Chomsky 1959), i kombination med rön om att färgkognition inte påverkades av språket utan var universell (Berlin \& Kay 1969), bidrog till att intresset för språklig relativism så gott som slocknade, och efterföljande årtionden såg i stället en häftig kritik av relativistiska tankeströmningar. Psykolingvisten Steven Pinker skrev exempelvis i sin bok The language instinct (1994) att $»[\mathrm{n}] \mathrm{o}$ one is really sure how Whorf came up with his outlandish claims» (s. 57) om språkets inverkan på tanken, samt att »[t]here is no scientific evidence that languages dramatically shape their speakers' ways of thinking» (s. 58, tillagd kursivering). Anglicisten Geoffrey Pullum (1988), å sin sida, sammanfattade frågan som »utterly boring, even if true» (s. 166). Mycket av denna kritik var uppbyggd kring en halmdocka, i det att Whorfs idéer tenderade att framställas som genomgripande radikala eller ogenomtänkta ${ }^{1}$, vilket gjorde dem till ett mer lovligt byte. Detta ledde till att debatten och meningsutbyten om språklig relativism ofta lämnade mycket att önska, vilket fångas i följande passage:

Current discourse on the topic of language and mind is at about the intellectual level of a chat show on the merits of democracy. Ideological nonsense, issued by famous scholars, fills the air, even the scientific journals. (Levinson 2003 s. 25)

\footnotetext{
${ }^{1}$ Whorfs teorikomplex var ganska spretigt och det går att finna både starkare och mildare påståenden om språkets inverkan på tanken.
} 
Utvecklingen vände i slutet av 1990-talet, då grunden lades för modern forskning kring språk och tanke under det som kommit att kallas den språkrelativistiska renässansen.

\section{Samtida forskning kring språk och tanke}

Det framhålls ofta att den språkrelativistiska renässansen föregicks och möjliggjordes av olika faktorer såsom framväxten av kognitiv semantik, ett intresse för andra perceptuella domäner än färg, och, framför allt, en definition och operationalisering av begreppen språk och tanke (t.ex. Gumperz \& Levinson 1996, Gentner \& Goldin-Meadow 2003). Denna sistnämnda faktor är utan tvekan ett fundament för empirisk forskning kring språklig relativism, och baseras i hög utsträckning på Lucys arbeten (Lucy 1992a, 1992b). Enligt Lucy bör språk (i ett relativistiskt sammanhang) definieras som en uppsättning semantiska distinktioner som realiseras med viss frekvens i grammatiska och/ eller lexikala kategorier. Den faktiska användningen av en given semantisk distinktion hos en språkgrupp bör mätas. Resonemanget bakom detta argument är att frekvent tillämpade distinktioner är mer sannolika att påverka tanken än distinktioner som inte görs särskilt ofta. Det är med andra ord sällan tillräckligt att referera till deskriptiva grammatikor för att påvisa förekomsten av en viss semantisk distinktion: data på faktiskt språkbruk är nödvändigt.

Begreppet tanke, å sin sida, kan definieras längs en rad kognitiva- och varseblivningsprocesser. Detta innefattar sådant som kategorisering och klassificering (vilka båda inkluderar ett element av likhetsbedömning), minne och visuell perception. I likhet med Lennebergs (1953) argument, bör den uppmätta tankeprocessen vara icke-verbal i det att den inte äger rum under själva talakten - eller inbegriper talförståelse för den delen. ${ }^{2}$ Lucy argumenterar också för att språkrelativistisk forskning rimligen måste anta en komparativ ansats, vilket inbegriper jämförelsen av två eller flera språkliga grupper. Att studera en semantisk distinktions eventuella effekter på tanken inom enbart en språkgrupp skulle sakna ett nödvändigt kontrollinslag, hävdar Lucy, och göra det omöjligt att dra slutsatser om språkspecifika effekter (vi återkommer framgent till detta argument).

${ }^{2}$ En ansats som däremot undersöker tankeprocesser under själva talakten och talförståelse är Thinking-for-Speaking (se vidare Slobin 1996, 2003). 


\section{Rörelsekognition}

Den metodologi som etablerades under 1990-talet tillämpas i stor utsträckning inom skilda perceptuella domäner. En sådan domän, som är dynamisk till sin natur, är rörelse. Världens språk uppvisar systematiska skillnader i hur de kodar olika komponenter av vissa rörelseskeenden. Vissa språk (t.ex. svenska) anger information om rörelsesätt (eng. manner) i huvudverbet och information om rörelsebana (eng. path) i verbpartiklar, medan andra språk (t.ex. spanska) i stället använder huvudverbet för rörelsebaneinformation och på valfri basis kodar information om rörelsesätt i exempelvis gerundiva konstruktioner (Talmy 2000). Exemplet nedan illustrerar detta med svenska och spanska.

$\begin{array}{llll}\text { Björnen } & \text { sprang } & \text { in } & \text { i grottan } \\ & \text { SÄTT } & \text { BANA } & \\ \text { El oso } & \text { entró } & \text { en la cueva } & \text { (corriendo) } \\ & \text { BANA } & \text { SÄTT } & \end{array}$

'Björnen äntrade (sprang in i) grottan'

Språktypen med information om rörelsebana i verbpartikel betecknas satellitspråk enligt Talmys typologi, och typen som uttrycker denna information i huvudverbet kallas verbbaserade språk. Ytterligare en språktyp, så kallade ekvipollenta språk (t.ex. kinesiska och thai), kodar både rörelsebana och -sätt i serieverbskonstruktioner (t.ex. Chen \& Guo 2009), vilket ger en mer jämbördig relation mellan dessa semantiska distinktioner ur ett informations-struktursperspektiv. Evidens över hur talare av dessa skilda språktyper använder olika verbkonstruktioner har samlats in genom återberättelseuppgifter, korpusanalys etc. (Berman \& Slobin 1994). Har då denna tvärspråkliga variation någon inverkan på hur talare av dessa språk faktiskt tänker om rörelse?

Montero-Melis och Bylund (2017) undersökte denna fråga med fokus på kausativa rörelseskeenden i spanska och svenska. ${ }^{3}$ Som ett första steg fick talare av dessa språk beskriva en serie videoklipp som visade en figur uträtta olika saker (rulla in ett hjul i en grotta, skjuta in en bil i ett garage etc.). Beskrivningarna visade att svensktalande var mer benägna än spansktalande att ange information om rörelsesätt, vilket tjänade till att påvisa skillnader $\mathrm{i}$ faktiskt språkbruk mellan grupperna. I det andra steget fick en annan uppsätt-

\footnotetext{
${ }^{3}$ Kausativ rörelse är ett skeende i vilket en agent utövar något slags kraft på en entitet, till exempel skjuta in en skottkärra i en bod, knuffa in en björn i en grotta etc. (Talmy 1988).
} 
ning deltagare titta på videoklippen och sedan fritt arrangera dem på en yta beroende på hur lika/olika de ansågs vara. Detta likhetsbedömningstest, som alltså var icke-verbalt till sin natur, gav vid handen att de svensktalande oftare arrangerade sina videoklipp enligt rörelsesätt, medan de spansktalande inte fäste lika stor vikt vid denna dimension (utan i stället lade mer vikt vid rörelsebana). Detta tolkades som evidens för språkets inverkan på tanken. Vad som emellertid inte kunde fastställas var huruvida dessa tvärspråkliga skillnader i kognition uppstod som en följd av ett slags vanemässigt tänkande om rörelsesätt som uppstår som en konsekvens av att på regelbunden basis koda denna distinktion, eller om det var en effekt av subvokalisering, i det att talarna under själva arrangeringsprocessen beskrev och satte etiketter på skeendena tyst för sig själva. Andra studier har nämligen visat att subvokalisering kan äga rum under denna typ av lite mer kognitivt krävande uppgifter (t.ex. Gennari m.fl. 2002, Athanasopoulos \& Bylund 2013).

I syfte att kasta ljus över denna fråga implementerades i ett tredje steg en så kallad interferensbetingelse, vilken gick ut på att en ny grupp deltagare genomförde samma arrangemangsuppgift men ombads samtidigt att upprepa sifferserier (t.ex. 67, 94, 21) under varje nytt videoklipp de såg. Grundidén i denna design är att minska möjligheten för subvokalisering genom att engagera språksystemet i en annan uppgift. Resultaten från interferensbetingelsen synliggjorde inga påvisbara skillnader mellan spansktalande och svensktalande - $\mathrm{i}$ stället använde sig bägge grupperna i högre utsträckning av rörelsebana i sina arrangemang. Med andra ord tycks den tvärspråkliga variation som dokumenterades i steg två ha uppstått som en funktion av subvokalisering, och inte vanemässiga tankemönster om rörelsesätt och -bana. Dessa resultat visar också att icke-verbala experiment inom språkrelativistisk forskning inte nödvändigtvis betyder att språket är helt frånvarande under utförandet av själva uppgiften: i stället bör dessa experiment, som tidigare nämnts, förstås som icke-verbala i bemärkelsen att den beroende variabeln är resultatet av en process som inte inbegriper öppen eller uttalad språkproduktion eller -förståelse.

Det faktum att en del språkrelativistiska effekter försvinner under interferensbetingelse har av vissa tolkats som bevis på att språkets inverkan på tanken är av det ytliga slaget, och enkelt kan inhiberas (Gleitman \& Papafragou 2013). Ett annat synsätt vore att se dessa fynd som bevis för att språket oundvikligen brukas av människan som ett redskap i hennes mentala aktiviteter (Language Acquisition and Conceptual Development 2001), och att dess effekter på tanken endast kan stängas av genom mer eller mindre artificiellt ingripande. 


\section{Tidskognition}

En annan perceptuell domän som beforskats i vid utsträckning är tid. Till skillnad från rörelse är tid abstrakt: vi kan inte se eller röra vid tid, men likväl är tid en oerhört central dimension i mänsklig tillvaro. Som framgår av artikelns inledande exempel om aymara är det vanligt bland världens språk att låna rumsliga begrepp för att uttrycka temporala förhållanden. Detta gäller också för tidsförlopp, eller duration. I germanska språk uttrycks duration ofta i termer av längd: ett långt möte, en kort intervju etc., medan andra språk såsom grekiska i stället använder sig av referenser till mängd: megali synandisi översätts idiomatiskt till 'ett långt möte' men betyder bokstavligen 'ett stort möte'. Casasanto m.fl. (2004) och Bylund och Athanasopoulos (2017) undersökte huruvida dessa rumsligt baserade metaforer faktiskt ger upphov till olika sätt att uppfatta tid, med fokus på engelska, svenska och indonesiska (längdbas), samt grekiska och spanska (mängdbas). Genom internetsökningar kunde konstateras att det i de tre första språken är långt vanligare med längduttryck för duration. I de fall då mängduttryck för tid förekommer har dessa vanligen en annan tolkning än duration: till exempel jag har lagt ner så mycket tid på projektet betyder snarare att något skett vid upprepade tillfällen och/eller varit krävande, än att det var utdraget i ett och samma tidsspann. För grekiska och spanska gällde motsatt förhållande, då mängdbaserade metaforer fungerade som det icke-markerade uttrycket för duration, och metaforer med längdbas i stället tjänade ett slags stilistisk funktion. ${ }^{4}$

Mot bakgrund av dessa användningsmönster testade Casasanto m.fl. (2004) och Bylund och Athanasopoulos (2017) huruvida språkens talare uppvisade motsvarande tvärspråkliga variation i sin uppfattning av tid, genom tillämpningen av ett tidsimitationstest av psykofysisk natur. I detta experiment fick deltagarna se på en datorskärm hur antingen linjer växte från höger till vänster, eller hur behållare fylldes nerifrån och upp. Deras uppgift bestod i att efter varje linje eller behållare göra en av två saker: 1) återskapa den tid det tagit för animationen att växa, genom att med hjälp av musklick härma tidsspannet; 2) återskapa den fysiska tillväxt som animationen visade, genom musklick över skärmen (detta var en kontrolluppgift). Manipulationen i testet var sådan att deltagarna kunde se en linje eller behållare växa $7 \mathrm{~cm}$ med en duration av 3

\footnotetext{
${ }^{4}$ Notera dock att spanska använder sig i mindre utsträckning av mängdmetaforer än grekiska. Det går på spanska till exempel inte att säga una reunión grande (bokstavligen 'ett stort möte') i betydelsen 'ett långt möte'. För att uttrycka mötets längd måste i stället längdmetafor brukas: una larga reunión ('ett långt möte').
} 
sekunder, eller $10 \mathrm{~cm}$ med en duration av 3 sekunder. För att korrekt härma tidsspannet var det alltså nödvändigt att fullständigt bortse från animationernas fysiska tillväxt. Detta visade sig emellertid vara lättare sagt än gjort. De engelska, indonesiska och svenska deltagarna lät sig förledas av linjernas fysiska längd i sina reproduktioner av tid, i så måtto att linjer som växte längre i rymd också uppfattades som längre i tid. Motsatt förhållande gällde för talare av grekiska och spanska, som i stället i högre utsträckning lät sig förledas av behållarnas fyllnad i sina tidsimitationer. Dessa resultat tycks med andra ord visa att språkspecifika metaforer kan påverka något så fundamentalt som tidsuppfattning.

Det finns emellertid en manipulation som kan göras för att testa, i likhet med studierna om rörelsekognition, vilken typ av språkliga effekter det handlar om. I det ovan beskrivna experimentet av Cassanto m.fl. fick deltagarna inför varje animation, för att veta huruvida de skulle uppskatta tid eller tillväxt, se ordet tid tillsammans med ett timglas eller avstånd/volym tillsammans med ett kryss. I en ytterligare betingelse testade därför Bylund och Athanasopoulos (2017) huruvida förekomsten av detta språkliga material hade någon inverkan på resultatet. Det visade sig att när de språkliga etiketterna tagits bort och endast symbolerna kvarstod försvann också de tvärspråkliga skillnaderna i tidsuppfattning. Oavsett språklig bakgrund lät deltagarna sig förledas av linjernas tillväxt - men inte behållarnas fyllnad - i sin återskapelse av tidsspann. Dessa resultat kan tolkas inom ramen för prediktiv processning (Lupyan \& Clark 2015), enligt vilken olika typer av informationskällor spelar in vid perceptuella och kognitiva processer. Språket ses här som en typ av informationskälla som kan influera uppfattningen av tingens tillstånd, men i frånvaro av språket spelar andra informationskällor in - såsom den förkroppsligade erfarenheten att längre sträckor också tar längre tid att tillryggalägga.

Rönen från forskning kring rörelse och tid, men också rums-, färg- och föremålskognition, visar att frågan om huruvida språket påverkar tanken inte kan besvaras med enkelt »ja» eller »nej» och därför till och med tycks vara felställd. I stället för att konceptualisera språkets inverkan på tanken i binära termer försöker man inom samtida forskning förstå vilka kognitiva och perceptuella processer som påverkas under vilka omständigheter av vilka språkliga kategorier (t.ex. Lupyan 2012). Detta mer nyanserade angreppssätt gentemot språk och tanke gör också att man undviker att falla tillbaka i det skyttegravskrig som under förra seklet rådde mellan universalister och relativister. 


\section{2}

\section{Flerspråklig relativism}

Om språkspecifika kategorier tycks kunna påverka vissa tankeprocesser, hur ser det då ut hos flerspråkiga individer vars språk har olika semantiska distinktioner? Tidiga verk om språk och tanke, såsom till exempel von Humboldts och Whorfs skrifter, innehöll allmänna anmärkningar om flerspråkighet, till exempel att inlärningen av ett nytt språk innebär tillägnandet av en ny världssyn, eller att global enspråkighet skulle leda till en förlust av tankemångfald och således global enögdhet. Ett empiriskt engagemang i frågan saknades emellertid. I den debatt om språklig relativism som ägde rum under senare hälften av 1900-talet dök, intressant nog, flerspråkighet upp som ett argument mot språkets inverkan på tanken. Det hävdades i denna anda att om språket verkligen påverkar tanken skulle tvåspråkiga talare lida av diverse psykologiska problem, närmast personlighetsklyvning, på grund av att de inte skulle kunna förmedla upplevelser mellan sina språk och bete sig annorlunda beroende på vilket språk de använde (Macnamara 1970). Eftersom mental ohälsa inte tycktes vara högre hos flerspråkiga kunde man således dra slutsatsen att språket inte påverkar tanken.

Ett annat anmärkningsvärt förhållningssätt gentemot flerspråkighet inom relativistisk forskning har bestått $i$ att behandla flerspråkiga testdeltagare som enspråkiga. Ett exempel på detta återfinns i Berlin och Kays (1969) studie om färgkategorier, som testade färgkategorisering i ett stort antal språk. Ett problem med deras deltagare var dock att många av dem som representerade andra språk än engelska var bosatta i USA och talade engelska. Att deras färgkategorisering i vissa avseenden liknade engelsktalandes - trots annorlunda uppsättningar med färgtermer - kan således vara en produkt av deras flerspråkighet, snarare än (eller i komplement till) ett slags universell mänsklig färgkognition. ${ }^{5}$ Det finns också exempel på studier i vilka deltagarnas flerspråkighet deklarerats öppet av författarna och sedan avskrivits som en icke-faktor. I sin studie av kategorisering av rumsliga relationer fann Munnich m.fl. (2001) inga skillnader mellan talare av koreanska och engelska, trots att språken uppvisar särdeles olika semantiska distinktioner härvidlag. Det faktum att de koreanska deltagarna talade engelska och var bosatta i USA hade, enligt författarna, inga konsekvenser för tolkningen av resultaten, eftersom inlärningen av engelska skett efter 12 års ålder. Detta, hävdade man med referens till Johnson och Newports (1989) studie om den kritiska perioden, betydde att ingen av de korean-

\footnotetext{
${ }^{5}$ Detta medgavs också decennier senare av en av författarna, Paul Kay, i ett blogginlägg.
} 
ska deltagarna hade uppnått inföddlik behärskningsnivå i engelska. Det kan, å andra sidan, hävdas att det är mer relevant huruvida deltagarna hade tillägnat sig en sådan nivå i engelska att deras spatiala kognition skulle kunna påverkas, inte huruvida de var inföddlika i språket eller ej.

Senare studier har visat att L1-specifik kognitiv processning kan påverkas även hos talare som endast har grundläggande behärskning $i$ ett L2, och till och med fortfarande är bosatta i L1-miljön och således kan antagas ha hög L1-input och hög L1-behärskning (Athanasopoulos m.fl. 2011, Athanasopoulos, Damjanovic, m.fl. 2015, Bylund \& Athanasopoulos 2015). Exempelvis fann Athanasopoulos m.fl. (2011) att L1-talare av japanska med bosättning i Japan var påverkade av sin L2-engelska när de kategoriserade olika nyanser av blått (japanska har till skillnad från engelska mer än en basterm för färgen blå). Dessa rön har potentiellt långtgående implikationer för sådana studier som jämfört två språkgrupper varav den ena behärskar den andras språk, och sedan inte funnit någon påvisbar tvärspråklig variation i kognition eller perception (t.ex. Berlin \& Kay 1969, Munnich m.fl. 2001, Loucks \& Pederson 2010).

\section{Flera språk, flera sinnen?}

De studier som systematiskt undersökt flerspråkighet och tanke tycks visa att det mänskliga sinnet är tämligen dynamiskt: inlärningen av ett nytt språk, eller samexistensen av två språkliga system kan ta sig i en mängd olika uttryck i termer av språkspecifika kognitiva processer. Pavlenko $(1999,2005)$ har $\mathrm{i}$ detta hänseende klassificerat ett antal olika kognitiva påverkansresultat hos flerspråkiga talare. En av dessa är så kallad kognitiv omstrukturering (se även Athanasopoulos 2006), vilken går ut på att kognition inom en given perceptuell domän genomgår en förändring som en funktion av andra-/främmandespråksinlärning. Ett exempel på detta återfinns i Athanasopoulos, Damjanovic, m.fl.:s (2015) undersökning av engelsktalande med bosättning i England som studerade tyska på universitetsnivå. Engelska och tyska skiljer sig åt i kategorin grammatisk aspekt, i så mån att engelska kodar pågåendefasen av ett skeende (genom den progressiva verbändelsen -ing) medan tyska saknar denna typ av grammatisk kategori. Detta får konsekvenser för hur rörelseskeenden beskrivs och kategoriseras med avseende på slutpunkter (t.ex. gå på en väg vs gå till ett hus) (Carroll \& von Stutterheim 1993, Bylund 2008, von Stutterheim m.fl. 2012, Athanasopoulos \& Bylund 2013). Resultaten från studien av Athanasopoulos, Damjanovic, m.fl. visade att behärskningsnivå och rörelsekatego- 
risering gick hand i hand: ju högre behärskning i tyska inlärarna hade, desto mer benägna var de att para ihop rörelseskeenden som liknade varandra med avseende på rörelsens slutpunkt, i likhet med infödda talare av tyska. Inlärarna hade också olika erfarenheter av att ha vistats i tyskspråkiga miljöer, och denna variabel uppvisade ett mindre linjärt förhållande till rörelsekategorisering. Individer med både kortare och längre tysk vistelsetid uppvisade högre likhet med tyska kategoriseringsmönster (i synnerhet den senare gruppen), medan individer med medellång vistelsetid i stället liknade engelska preferenser. Dessa resultat diskuterades med utgångspunkt i kognitiva modeller för U-formad inlärning (Rogers m.fl. 2004).

En fråga som studiedesignen ovan inte kan besvara är huruvida inlärarna hade betett sig annorlunda om de mottagit experimentinstruktionerna på engelska i stället för på tyska. Med andra ord, är det möjligt att elicitera olika kognitiva mönster hos flerspråkiga individer genom att manipulera den språkliga kontexten? Empirisk evidens tycks visa att så är fallet (se dock Filipović 2011). I en senare studie undersökte Athanasopoulos m.fl. (2015) kategorisering av rörelseskeenden (med samma paradigm som ovan) hos tvåspråkiga talare av L1-tyska och L2-engelska. Resultaten visade att de deltagare som mottagit instruktioner på tyska betedde sig som (funktionellt) enspråkiga tysktalande, medan de som fick instruktioner på engelska i stället betedde sig som engelsktalande. Denna typ av kontextbundet beteende verkar inte vara begränsat till rörelsedomänen, utan förekommer till exempel också i tidskognition. Studier av Miles m.fl. (2011) och Bylund och Athanasopoulos (2017) har visat att tvåspråkiga talare kan skifta mental representation av tid beroende på närvaron av vissa språkliga element i experimentet. I den senare studien, exempelvis, som använde sig av tidsimitationsparadigmet (beskrivet ovan i avsnittet Tidskognition), kunde man se att spansk-svenskt tvåspråkiga uppvisade språkspecifika tidsuppfattningar: i den betingelse då de växande linjerna föregicks av svensk instruktion reproducerade deltagarna tid på samma sätt som (funktionellt) enspråkiga svensktalande, vilket innebar att de lät sig förledas av linjernas längd i sin reproduktion av duration. När samma individer utförde uppgiften med spansk instruktion uppvisade de däremot ingen sådan effekt, i likhet med enspråkiga spansktalande. Omvänt förhållande gällde för betingelsen med behållare (notera att ordningen för spansk/svensk instruktion motbalanserades).

Intressant nog påminner dessa dubbla beteendemönster om det Macnamara (1970) framförde som en omöjlighet: att flerspråkiga beter sig annorlunda beroende på vilket språk de använder. Men i stället för att kullkasta principen om 
språklig relativism tycks insikter från flerspråkighet och tanke kunna erbjuda vissa metodologiska fördelar. Den etablerade metoden att jämföra hur talare av olika språk beter sig på en viss uppgift innehåller en möjlig förväxlingsfaktor i det att eventuella kognitiva skillnader som påträffas mellan deltagargrupperna inte alltid med absolut säkerhet kan tillskrivas tvärspråkliga skillnader. Det är med andra ord svårt att fastställa att språkliga kategorier, och inte någon okänd kulturell faktor, ligger bakom effekten (Levinson 1997). Detta kan i viss mån åtgärdas med experimentella manipulationer men faktum kvarstår likväl att en jämförelse mellan två olika grupper utförs. Testar man däremot flerspråkiga talare uppstår möjligheten att göra åtminstone två typer av inomgruppsliga analyser. För det första kan en och samma individ testas under olika språkliga betingelser, såsom gjorts ovan i undersökningarna av rörelsekognition och tidskognition. Finner man att det kognitiva beteendemönstret varierar därefter kan detta utgöra en starkare tolkningsgrund för att effekten drivs av just språkliga faktorer (antalet okända variabler minskar). För det andra kan man med flerspråkiga deltagare också undersöka huruvida variation i språklig erfarenhet och bakgrund ger upphov till motsvarande kognitiv variation, såsom gjorts i studierna ovan med korrelationsanalyser mellan språkbehärskning och beteende. Detta förfarande erbjuder åter en starkare grund för tolkningen av språkets effekter på tanken.

\section{Den flerspråkiga bakgrunden}

Att mäta effekten av individuella skillnader i språklig bakgrund är av vikt inte enbart för resonemang om språk och tanke, utan också för att förstå de faktorer som formar det flerspråkiga sinnet. Bland dessa faktorer ingår språkbehärskning, användningsfrekvens av språken, inlärningsålder, inlärningskontext och vistelsetid i olika språkliga miljöer. Nedan följer en genomgång av de tre faktorer som hittills beforskats mest.

\section{Språkbehärskning}

En nödvändig förutsättning för att en given semantisk distinktion ska kunna påverka en individs tankeprocesser är att distinktionen behärskas av individen. Detta gäller både i situationer av andraspråksinlärning i vilka en ny distinktion tillägnas, men också i språkförlustsammanhang (så kallad attrition), då en distinktion antingen vidmakthålls eller förloras. Ett antal studier har visat att graden av språkbehärskning kan påverka kategoriseringen av exempelvis före- 
mål (Athanasopoulos 2007, Kurinski \& Sera 2011), rumsliga relationer (Park \& Ziegler 2014) och rörelse (Athanasopoulos, Damjanovic m.fl. 2015, MonteroMelis m.fl. 2016). Det finns emellertid andra studier som inte kunnat fastställa något sådant samband (Cook m.fl. 2006, Athanasopoulos 2009, Bylund m.fl. 2013, Bylund \& Athanasopoulos 2015).

En central fråga i sammanhanget är givetvis hur behärskning operationaliseras. Det finns i de studier som publicerats till dags dato en avsevärd variation i detta avseende. Vissa har mätt global behärskning antingen genom självrapportering eller formella test (som i olika utsträckning varit standardiserade), andra har mätt behärskning av den specifika semantiska distinktionen ifråga (ofta genom empiriska men icke-standardiserade test). Denna uppsjö av tillvägagångssätt gör det svårt att dra några generella slutsatser om språkbehärskningens roll för flerspråkig kognition. Inom begreppsbildningsstudier har specifik behärskning, men inte global behärskning, visat sig vara en mer pålitlig faktor för att förutspå talares verbala beteende. Exemplvis fann Bylund och Jarvis (2011) i sin studie av spansk-svenskt tvåspråkiga att specifik behärskning av aspektuella distinktioner i spanska (perfektiv vs imperfektiv aspekt) korrelerade med deltagarnas angivelse av slutpunkter i rörelsebeskrivningar: ju högre behärskning, desto lägre var sannolikheten att beskrivningarna innehöll slutpunkter, i likhet med enspråkiga spansktalande. Något sådant statistiskt samband påträffades inte för global behärskning och slutpunktsangivelse.

Det är möjligt att det förhåller sig på samma sätt med kognitivt beteende. Ett potentiellt problem när man undersöker denna fråga är dock att specifik behärskning tenderar att korrelera med global behärskning, vilket introducerar en potentiell förväxlingsfaktor. Vad som skulle behövas är dock inte bara känsligare test, utan också, som Brown och Gullberg föreslår (2012), standardiserade test som möjliggör dels ett slags klassificering av deltagarnas språkliga nivå, och dels jämförelser mellan olika studiers deltagare.

En sista observation bör göras om behärskningsfaktorn. Ett underliggande antagande i resonemanget ovan är att semantisk och konceptuell representation kan fångas i ett språktest. Insikter från studier som undersöker gester hos flerspråkiga visar emellertid att sådan representation inte alltid fångas i talet. Exempelvis fann Brown och Gullberg (2008) att japansk-engelska tvåspråkiga gjorde samma semantiska distinktioner i tal som japanska enspråkiga talare när de beskrev rörelseskeenden med avseende på rörelsebana, men att de i sina gester kodade ytterligare distinktioner (såsom rörelsesätt). Enbart verbala data (eliciterade genom tal eller specifika behärskningstester) är med andra ord inte alltid tillräckliga för att nå insikter om semantisk representation. 


\section{Användningsfrekvens}

Användningsfrekvens av språk(en) är en annan faktor som visats påverka kognitivt beteende hos flerspråkiga. Tolkningen av denna effekt följer samma logik som förslaget att relativistisk forskning bör undersöka språkliga kategorier som är obligatoriska och frekvent tillämpade: ju oftare en viss konstruktion används desto mer stärks dess representation, vilket i sin tur ökar dess mentala prominens (Langacker 2000). Ett flertal studier har kunnat dokumentera ett samband mellan användningsfrekvens av ett givet språk och kognitivt beteende (Athanasopoulos m.fl. 2011, Bylund m.fl. 2013, Bylund \& Athanasopoulos 2014a, 2015, Park \& Ziegler 2014). Exempelvis fann Athanasopoulos m.fl. (2011) att japansk-engelskt tvåspråkiga som använde engelska oftare också uppvisade mer engelskliknande mönster i sin kategorisering och minne av färg. Användningsfrekvens har hittills inom forskningen definierats i breda termer, då det kunnat inbegripa aktivt och passivt bruk, samt talat och skrivet språk, och vidare operationaliserats på olika vis (Likertskala, h/vecka, procentsats). För att öka förståelsen av denna faktor kan det vara viktigt att $\mathrm{i}$ mätningarna ta hänsyn till modalitet (talad/skriven) och interaktivitet (passiv exponering eller aktiv produktion). Det sistnämnda kan vara av särskild vikt då neurolingvistisk evidens har visat att produktion har en starkare effekt på aktiveringsnivån av språkliga element jämfört med förståelse (Paradis 2004).

En dimension av användningsfrekvens som är viktig att ha i åtanke är att den också kan påverka en annan individuell bakgrundsfaktor, nämligen språkbehärskning. Forskning kring flerspråkig utveckling, i synnerhet attrition/ språkförlust, har visat att den frekvens med vilken ett språk talas kan påverka vidmakthållandet av vissa distinktioner (t.ex. Bylund m.fl. 2010, Schmid \& Dusseldorp 2010). En mer befogad tolkning av effekterna av användningsfrekvens kan således göras under förutsättning att ett eventuellt förväxlingsförhållande till språkbehärskning kan avskrivas med hjälp av statistiska analyser av förhållandet mellan användningsfrekvens och behärskning.

\section{Ålder för språkinlärning}

Den tredje centrala faktorn för kognitivt beteende är åldern vid vilken språken tillägnades. Denna faktor kan utöva två olika typer av influens (Bylund \& Athanasopoulos 2014b). Å ena sidan tycks inlärningsålder påverka semantisk och konceptuell representation, i så mån att simultant tvåspråkiga och mycket tidiga L2-inlärare är benägna att uppvisa liknande kategoriseringsmönster i bägge språken (t.ex. Ameel m.fl. 2009; Kersten m.fl. 2010) - även om dessa kan 
variera mellan olika begreppsbildningsprocesser (Bylund 2011). Dessa kategoriseringsmönster hamnar ofta »mittemellan» de enspråkiga talarnas beteende. Sent tvåspråkiga tycks i stället i högre utsträckning uppvisa den typ av dubbla språkspecifika beteendemönster som beskrivits ovan (avsnittet Flera språk, flera sinnen?) (Pavlenko 2005). En möjlig orsak bakom dessa skillnader är att tidigt tvåspråkiga utvecklar sina språk i samma takt som de tillägnar sig en begreppsapparat, samt att de ofta lär sig språken i samma (informella) kontext. Sent tvåspråkiga, i synnerhet de som lär sig L2 i en främmandespråkskontext, har således andra förutsättningar. Enligt denna tolkning av inlärningsålder är det alltså inte neurobiologisk mognad som påverkar kognitivt beteende, utan omständigheterna associerade med tidig respektive sen inlärning.

Den andra typen av influens som inlärningsålder kan utöva relaterar till språkbehärskning. Det finns över 100 studier inom andraspråksforskningen som visar att inlärningsålder korrelerar negativt med behärskningsnivå (t.ex. Johnson \& Newport 1989, Abrahamsson \& Hyltenstam 2009, Granena \& Long 2013), samt också växande evidens från attritionsfältet som visar positiva korrelationer mellan vidmakthållande och startålder för attrition (t.ex. Bylund 2009b, 2009a, Schmid 2012). I den mån behärskning kan sägas påverka kognitivt beteende kan med andra ord inlärningsålder antagas modulera denna effekt. Exempelvis fann Athanasopoulos och Kasai (2008) att både inlärningsålder och L2-behärskning korrelerade med kategoriseringspreferenser av föremål, men även att inlärningsålder och L2-behärskning korrelerade sinsemellan. Efter en partiell korrelation kvarstod endast effekterna av behärskning. En möjlig tolkning skulle alltså vara att betrakta effekterna av inlärningsålder som indirekta, i den mening att de löper via behärskningsnivå. Inte heller i detta fall tillskrivs alltså några direkta effekter till neurobiologisk mognad.

Som framgår av resonemangen ovan är de faktorer som styr flerspråkigt kognitivt beteende ofta relaterade sinsemellan. Detta kan ibland försvåra tolkningen, i synnerhet hos de studier som endast undersöker en eller ett par av dessa faktorer, och därför inte står i position att utröna eventuella förväxlingsförhållanden. Det är icke desto mindre absolut nödvändigt att ta hänsyn till faktorer i flerspråkig bakgrund, dels för att bättre förstå dynamiken i det flerspråkiga sinnet, dels för att undvika svepande uttalanden om flerspråkighet och tanke i vilka flerspråkighet ses som ett enhetligt, monolitiskt fenomen. 


\section{Med framtiden i blickfånget}

Forskning kring språk och tanke har kommit en lång väg sedan Herodotos iakttagelser om skriftspråkets riktning och dess möjliga effekter på sinnelaget. Den stora merparten av utvecklingen har skett under de senaste 30 åren, då ämnet språklig relativism gått från att karakteriseras av en tämligen binär frågeställning till en mer nyanserad, empirisk ansats som undersöker språkliga kategoriers inverkan på olika kognitiva och perceptuella processer. En sidoeffekt av denna utveckling som bör tas i beaktande är det faktum att forskning kring språklig relativism också gått till att bli mer och mer bunden till laboratoriet. Experiment som genomförs under kontrollerade former är förvisso en förutsättning för att etablera kausala förhållanden och nå djupare insikter om språkets plats i det mänskliga sinnets arkitektur - det var ju, trots allt, denna typ av metodologi som saknades i tidig forskning kring språk och tanke. Men detta innebär också att vår kunskap om språkets inverkan på tanken utanför en laboratoriekontext är begränsad (Sidnell \& Enfield 2012, Athanasopoulos \& Bylund 2020). Det går naturligtvis att hävda att laboratorieevidens om språkets inverkan på kategorisering kan generaliseras till allt slags beteenden $\mathrm{i} »$ verkliga livet», under premissen att kategorisering är hörnstenen i all mänsklig kognition (Harnad 2005). Även om det är ett kraftfullt argument kan det aldrig ersätta empirisk evidens för språkets effekter på beteenden i vardagslivet. En viktig uppgift för framtida forskning är därför att i större omfattning också generera data om språklig relativism med högre grad av ekologisk validitet. Detta kan uppnås genom till exempel observationsstudier av mänsklig interaktion och människans organisering av sin omgivning (t.ex. Hanks 1991, Sidnell \& Enfield 2012, Athanasopoulos \& Bylund 2020). Det är viktigt att understryka att den ena ansatsen inte ska ersätta den andra: snarare behövs bägge datatyper för att till fullo förstå språkets inverkan på sinnet.

Om forskning kring språk och tanke befinner sig på ett tidigt utvecklingsstadium är det nog befogat att påstå att forskning kring flerspråkighet och tanke ännu är i sin linda. Många frågor om kognitiv omstrukturering, dubbla beteendemönster och bakgrundsfaktorer återstår: det empiriska underlaget om dessa fenomen är i dagsläget för litet eller spretigt för att man ska kunna dra några definitiva slutsatser, men fungerar väl i hypotesgenererande syfte för uppföljnings- och replikeringsstudier. Ett skäl till att studera språklig relativism utifrån ett flerspråkigt perspektiv hänger, som nämnts ovan, ihop med de metodologiska fördelar denna urvalsgrupp erbjuder. Men det handlar också om att öka förståelsen för det flerspråkiga sinnet i sig. Enligt samtida uppskatt- 
ningar är över hälften av jordens befolkning flerspråkig (Aronin \& Singleton 2012). Flerspråkighet är med andra ord ett högst globalt fenomen. Att studera flerspråkighet och tanke handlar således också om ekologisk validitet: ett studium av språklig relativism som enbart engagerar sig i enspråkighet kommer aldrig att kunna ge en representativ bild av det mänskliga sinnets flexibilitet.

\section{Litteratur}

Abrahamsson, Niclas \& Hyltenstam, Kenneth, 2009: Age of onset and nativelikeness in a second language: listener perception versus linguistic scrutiny. I: Language Learning 59(2). S. 249-306.

Allan, Keith, 2004: Aristotle's footprints in the linguist's garden. I: Language Sciences 26(4). S. 317-342.

Ameel, Eef, Malt, Barbara C., Storms, Gert \& Van Assche, Fons, 2009: Semantic convergence in the bilingual lexicon. I: Journal of Memory and Language 60(2). S. 270-290.

Aronin, Larissa, \& Singleton, David, 2012: Multilingualism. Amsterdam: John Benjamins Publishing.

Athanasopoulos, Panos, 2006: Effects of the grammatical representation of number on cognition in bilinguals. I: Bilingualism: Language and Cognition 9(01). S. 89-96.

Athanasopoulos, Panos, 2007: Interaction between grammatical categories and cognition in bilinguals: The role of proficiency, cultural immersion, and language of instruction. I: Language and Cognitive Processes 22(5). S. 689-699.

Athanasopoulos, Panos, 2009: Cognitive representation of colour in bilinguals: The case of Greek blues. I: Bilingualism: Language and Cognition 12(01). S. 83-95.

Athanasopoulos, Panos, Bylund, Emanuel, Montero-Melis, Guillermo, Damjanovic, Ljubica, Schartner, Alina, Kibbe, Alexandra, Riches, Nick \& Thierry, Guillaume, 2015: I: Two Languages, Two Minds: Flexible Cognitive Processing Driven by Language of Operation. Psychological Science 26(4). S. 518-526.

Athanasopoulos, Panos \& Bylund, Emanuel, 2013: Does Grammatical Aspect Affect Motion Event Cognition? A Cross-Linguistic Comparison of English and Swedish Speakers. I: Cognitive Science 37(2). S. 286-309.

Athanasopoulos, Panos \& Bylund, Emanuel, 2020: Whorf in the Wild: Naturalistic Evidence from Human Interaction. I: Applied Linguistics, under utgivning.

Athanasopoulos, Panos, Damjanovic, Ljubica, Burnand, Julie \& Bylund, Emanuel, 2015: Learning to Think in a Second Language: Effects of Proficiency and Length of Exposure in English Learners of German. I: The Modern Language Journal 99(S1). S. 138-153.

Athanasopoulos, Panos, Damjanovic, Ljubica, Krajciova, Andrea \& Sasaki, Miho, 2011: Representation of Colour Concepts in Bilingual Cognition: The Case of Japanese Blues. I: Bilingualism: Language and Cognition 14(01). S. 9-17. 
Athanasopoulos, Panos, \& Kasai, Chise, 2008: Language and thought in bilinguals: The case of grammatical number and nonverbal classification preferences. I: Applied Psycholinguistics 29(01). S. 105-123.

Berlin, Brent \& Kay, Paul, 1969: Basic Color Terms: Their Universality and Evolution. Berkeley: University of California Press.

Berman, Ruth Aronson \& Slobin, Dan Isaac, 1994: Relating Events in Narrative: A Crosslinguistic Developmental Study. Mahwah, N.J.: Lawrence Erlbaum Associates.

Boas, Franz, 1911: Handbook of American Indian Languages. Cambridge: Cambridge University Press.

Brown, Amanda, \& Gullberg, Marianne, 2008: Bidirectional crosslinguistic influence in L1-L2 encoding of manner in speech and gesture: A study of Japanese speakers of English. I: Studies in Second Language Acquisition 30. S. 225-251.

Brown, Amanda, \& Gullberg, Marianne, 2012: Multicompetence and Native Speaker Variation in Clausal Packaging in Japanese. I: Second Language Research 28(4). S. $415-442$.

Bylund, Emanuel, 2008: Procesos de conceptualización de eventos en español y en sueco: diferencias translinguísticas. I: Revue Romane 43(1). S. 1-24.

Bylund, Emanuel, 2009a: Effects of age of L2 acquisition on L1 event conceptualization patterns. I: Bilingualism: Language and Cognition 12(3). S. 305-322.

Bylund, Emanuel, 2009b: Maturational Constraints and First Language Attrition. I: Language Learning 59(3). S. 687-715.

Bylund, Emanuel, 2011: Segmentation and Temporal Structuring of Events in Early Spanish-Swedish Bilinguals. I: International Journal of Bilingualism 15(1). S. 56-84.

Bylund, Emanuel, Abrahamsson, Niclas \& Hyltenstam, Kenneth, 2010: The Role of Language Aptitude in First Language Attrition: The Case of Pre-Pubescent Attriters. I: Applied Linguistics 31(3). S. 443-464.

Bylund, Emanuel \& Athanasopoulos, Panos, 2014a: Language and thought in a multilingual context: The case of isiXhosa. I: Bilingualism: Language and Cognition 17. S. 431-443.

Bylund, Emanuel \& Athanasopoulos, Panos, 2014b: Linguistic Relativity in SLA: Toward a New Research Program. I: Language Learning 64(4). S. 952-985.

Bylund, Emanuel \& Athanasopoulos, Panos, 2015: Televised Whorf: Cognitive Restructuring in Advanced Foreign Language Learners as a Function of Audiovisual Media Exposure. I: The Modern Language Journal 99(S1). S. 123-137.

Bylund, Emanuel \& Athanasopoulos, Panos, 2017: The Whorfian time warp: Representing duration through the language hourglass. I: Journal of Experimental Psychology: General 146. S. 911-916.

Bylund, Emanuel, Athanasopoulos, Panos \& Oostendorp, Marcelyn, 2013: Motion event cognition and grammatical aspect: Evidence from Afrikaans. I: Linguistics 51. S. 929-955.

Bylund, Emanuel \& Jarvis, Scott, 2011: L2 effects on L1 event conceptualization. I: Bilingualism: Language and Cognition 14 (Special Issue 01). S. 47-59. 
Carroll, Mary \& von Stutterheim, Christiane, 1993: The representation of spatial configurations in English and German and the grammatical structure of locative and anaphoric expressions. I: Linguistics 31(6). S. 1011-1042.

Casasanto, Daniel, Boroditsky, Lera, Phillips, Webb, Greene, Jesse, Goswami, Shima, Bocanegra-Thiel, Simon, Santiago-Diaz, Ilia, Fotakopoulo, Olga, Pita, Ria, Gil, David, Gentner, Dedre \& Regier, Thierry, 2004: How Deep Are Effects of Language on Thought? Time Estimation in Speakers of English, Indonesian, Greek and Spanish. I: Proceedings of the 26th Annual Conference Cognitive Science Society, red. av K. Forbus, Dedre Gentner, \& Terry Regier. Hillsdale, N.J.: Lawrence Erlbaum. S. 575-580.

Chen, Liang \& Guo, Jiansheng: 2009. Motion events in Chinese novels: Evidence for an equipollently-framed language. I: Journal of Pragmatics 41(9). S. 1749-1766.

Chomsky, Noam, 1959: A review of B. F. Skinner's Verbal Behavior. I: Language 35(1). S. 26-58.

Cook, Vivian, Bassetti, Benedetta, Kasai, Chise, Sasaki, Miho \& Takashi, Jun, 2006: Do bilinguals have different concepts? The case of shape and material in Japanese L2 users of English. I: International Journal of Bilingualism 10(2). S. 137-152.

Filipović, Luna, 2011: Speaking and Remembering in One or Two Languages: Bilingual vs. Monolingual Lexicalization and Memory for Motion Events. I: International Journal of Bilingualism 15(4). S. 466-485.

Fishman, Joshua A., 1960: A Systematization of the Whorfian Hypothesis. I: Behavioral Science 5(4). S. 323-339.

Gennari, Silvia P., Sloman, Steven A., Malt, Barbara C. \& Fitch, W. Tecumseh, 2002: Motion events in language and cognition. I: Cognition 83(1). S. 49-79.

Gentner, Dedre, \& Goldin-Meadow, Susan, 2003: Whither Whorf. I: Language in mind: advances in the study of language and thought, red. av Dedre Gentner \& Susan Goldin-Meadow. Cambridge, Mass.: MIT Press. S. 3-14.

Gleitman, Lila \& Papafragou, Anna, 2013: New perspectives on language and thought. I: The Oxford handbook of thinking and reasoning, red. av Keith J. Holyoak \& Robert G. Morrison. Oxford: Oxford University Press. S. 543-568.

Granena, Gisela \& Long, Michael H., 2013: Age of Onset, Length of Residence, Language Aptitude, and Ultimate L2 Attainment in Three Linguistic Domains. I: Second Language Research 29(3). S. 311-343.

Gumperz, John J. \& Levinson, Stephen C., 1996: Introduction: linguistic relativity reexamined. I: Rethinking linguistic relativity, red. av John J. Gumperz \& Stephen C. Levinson. Cambridge: Cambridge Univ. Press. S. 1-18.

Hanks, William F., 1991: Referential Practice: Language and Lived Space Among the Maya. Chicago: University of Chicago Press.

Harnad, Stevan, 2005: To Cognize is to Categorize: Cognition is Categorization. I: Handbook of Categorization, red. av Claire Lefebvre \& Henri Cohen. Amsterdam: Elsevier. S. 2-29.

Johnson, Jacqueline S. \& Newport, Elissa L., 1989: Critical period effects in second language learning: The influence of maturational state on the acquisition of English as a second language. I: Cognitive Psychology 21(1). S. 60-99. 
Kersten, Alan, Meissner, Christian, Lechuga, Julia, Schwartz, Bennett, Albrechtsen, Justin \& Iglesias, Adam, 2010: English Speakers Attend More Strongly than Spanish Speakers to Manner of Motion When Classifying Novel Objects and Events. I: Journal of Experimental Psychology: General 139(4). S. 638-653.

Kurinski, Elena \& Sera Maria D., 2011: Does learning Spanish grammatical gender change English-speaking adults' categorization of inanimate objects? I: Bilingualism: Language and Cognition 14(02). S. 203-220.

Langacker, Ronald W., 2000: Grammar and Conceptualization. Berlin: Walter de Gruyter.

Language Acquisition and Conceptual Development, red. av Melissa Bowerman \& Stephen Levinson. Cambridge, UK: Cambridge University Press 2001.

Lenneberg, Eric H., 1953: Cognition in Ethnolinguistics. I: Language 29(4). S. 463-471.

Lenneberg, Eric H. \& Roberts, John M., 1956: The Language of Experience: A Study in Methodology (Supplement till International Journal of American Linguistics, V22, No. 2, April). Bloomington: Literary Licensing, LLC.

Levinson, Stephen C., 1997: Language and Cognition: The Cognitive Consequences of Spatial Description in Guugu Yimithirr. I: Journal of Linguistic Anthropology 7(1). S. 98-131.

Levinson, Stephen C., 2003: Language and mind: let's get the issues straight! I: Language in mind: advances in the study of language and thought, red. av Dedre Gentner \& Susan Goldin-Meadow. Cambridge, Mass.: MIT Press. S. 25-46.

Loucks, Jeff \& Pederson, Eric, 2010: Linguistic and non-linguistic categorization of complex motion events. I: Event representation in language and cognition, Language Culture and Cognition, red. av Jürgen Bohnemeyer \& Eric Pederson. Cambridge: Cambridge University Press. S. 108-133.

Lucy, John A., 1992a: Grammatical Categories and Cognition. Cambridge, Mass.: Cambridge University Press.

Lucy, John A., 1992b: Language Diversity and Thought. Cambridge, Mass.: Cambridge University Press.

Lupyan, Gary, 2012: Linguistically modulated perception and cognition: The LabelFeedback Hypothesis. I: Frontiers in Psychology 3.

Lupyan, Gary \& Clark, Andy, 2015: Words and the World Predictive Coding and the Language-Perception-Cognition Interface. I: Current Directions in Psychological Science 24(4). S. 279-284.

Macnamara, John, 1970: Bilingualism and thought. Georgetown University 21 st Annual Round Table 21. S. 25-40.

Miles, Lynden K., Tan, Lucy, Noble, Grant, Lumsden, Joanne \& Macrae, Neil, 2011: Can a mind have two time lines? Exploring space-time mapping in Mandarin and English speakers. I: Psychonomic Bulletin \& Review 18(3). S. 598-604.

Montero-Melis, Guillermo \& Bylund, Emanuel, 2017: Getting the Ball Rolling: The Cross-Linguistic Conceptualization of Caused Motion. I: Language and Cognition 9(3). S. 446-472. 


\section{Emanuel Bylund}

Montero-Melis, Guillermo, Jaeger, T. Florian \& Bylund, Emanuel, 2016: Thinking Is Modulated by Recent Linguistic Experience: Second Language Priming Affects Perceived Event Similarity. I: Language Learning 66(3). S. 636-665.

Munnich, Edward, Landau, Barbara \& Dosher. Barbara Anne, 2001: Spatial language and spatial representation: a cross-linguistic comparison. I: Cognition 81(3). S. 171-208.

Núñez, Rafael \& Sweetser, Eve, 2006: With the Future behind Them: Convergent Evidence from Aymara Language and Gesture in the Crosslinguistic Comparison of Spatial Construals of Time. Cognitive Science 30(3). S. 401-450.

Paradis, Michel, 2004: A neurolinguistic theory of bilingualism. Amsterdam: John Benjamins.

Park, Hae In, \& Ziegler, Nicole, 2014: Cognitive shift in the bilingual mind: Spatial concepts in Korean-English bilinguals. I: Bilingualism: Language and Cognition 17. S. 410-430.

Pavlenko, Aneta, 1999: New approaches to concepts in bilingual memory. I: Bilingualism: Language and Cognition 2(03). S. 209-230.

Pavlenko, Aneta, 2005: Bilingualism and thought. I: Handbook of bilingualism: Psycholinguistic approaches, red. av Judith F. Kroll \& Annette M. B. de Groot. Oxford: Oxford University Press. S. 433-453.

Pinker, Steven, 1994: The language instinct: How the mind creates language. New York: Penguin Books.

Pullum, Geoffrey, 1988: The great Eskimo vocabulary hoax and other irreverant essays on language. London: Equinox.

Rogers, Timothy T., Rakison, David H. \& McClelland, James L., 2004: U-shaped curves in development: A PDP approach. I: Journal of Cognition and Development 5(1). S. 137-145.

Sapir, Edward, 1921: Language: An Introduction to the Study of Speech. New York: Harcourt.

Schmid, Monika S., 2012: The Impact of Age and Exposure on Bilingual Development in International Adoptees and Family Migrants: A Perspective from Holocaust Survivors. Linguistic Approaches to Bilingualism 2(2). S. 177-208.

Schmid, Monika S. \& Dusseldorp, Elise, 2010: Quantitative Analyses in a Multivariate Study of Language Attrition: The Impact of Extralinguistic Factors. I: Second Language Research 26(1). S. 125-160.

Sidnell, Jack \& Enfield, N. J., 2012: Language diversity and social action: A third locus of linguistic relativity. I: Current Anthropology 53(3). S. 302-333.

Slobin, Dan I., 1996: From 'thought and language' to 'thinking for speaking'. I: Rethinking linguistic relativity, red. av John J. Gumperz \& Stephen C. Levinson. Cambridge: Cambridge Univ. Press. S. 70-96.

Slobin, Dan I., 2003: Language and thought online: cognitive consequences of linguistic relativity. I: Language in mind: advances in the study of language and thought, red. Dedre Gentner \& Susan Goldin-Meadow. Cambridge, Mass.: MIT Press. S. 157-191. 
von Humboldt, Wilhelm. 1988: On Language: The Diversity of Human LanguageStructure and Its Influence on the Mental Development of Mankind. Cambridge: Cambridge University Press.

von Stutterheim, Christiane, Andermann, Martin, Carroll, Mary, Flecken, Monique $\&$ Schmiedtova, Barbara, 2012: How grammaticized concepts shape event conceptualization in language production: Insights from linguistic analysis, eye tracking data, and memory performance. I: Linguistics 50(4). S. 833-867.

Talmy, Leonard, 1988: Force dynamics in language and cognition. I: Cognitive Science 12(1). S. 49-100.

Talmy, Leonard, 2000: Toward a Cognitive Semantics I. Cambridge, MA: MIT Press. Whorf, Benjamin Lee, 1956: Language, Thought, and Reality: Selected Writings, red. av J. B. Carroll. Cambridge, Mass.: MIT Press. 